\title{
THE EFFECTS OF METHEDRINE AND OF LYSERGIC ACID DIETHYLAMIDE ON MENTAL PROCESSES AND ON THE BLOOD ADRENALINE LEVEL
}

BY

\author{
D. W. LIDDELL and H. WEIL-MALHERBE
}

From Runwell Hospital, Wickford, Essex

The psychological effects of drugs and their applications in psychiatry are of theoretical as well as practical interest, but their study has rarely penetrated beyond a description of symptoms and little is known of their mechanisms of action. Since a method for the estimation of adrenergic amines in blood has recently been developed (Weil-Malherbe and Bone, 1952) we decided to study the changes of blood adrenaline levels during drug action and to correlate them with mental changes. In this communication we report on results obtained with d-N-methylamphetamine hydrochloride ("methedrine") and lysergic acid diethylamide (L.S.D.).

The application of methedrine in psychiatry has been investigated by Levine, Rinkel, and Greenblatt (1948), Delay (1949), Rudolf (1949), Hope, Callaway, and Sands (1951) and Hoch, Cattell, and Pennes (1952b). In schizophrenic patients the drug is claimed to produce an increase of accessibility, emotional discharge, and verbalization of repressed or delusional material. Delay (1949), on the other hand, states that catatonic features, if present, are accentuated.

The psychological effects of L.S.D. in normal and psychotic subjects were first described by Stoll (1947) and his results were subsequently confirmed by Condrau (1949), Becker (1949), and Fischer, Georgi, and Weber (1951). DeShon, Rinkel, and Solomon (1952) studied the effects of L.S.D. on normal subjects and Busch and Johnson (1950), Forrer and Goldner (1951), and Hoch and others (1952a) similarly investigated its effects on psychotics. De Giacomo (1951) drew attention to the capacity of L.S.D., given in large doses by mouth, of producing symptoms of catatonia in schizophrenic patients, an effect resembling the action of bulbocapnine. Others have commented on the analogy with the action of mescaline.

Though the various authors tended to stress different symptoms as the chief characteristic of L.S.D. action, all are agreed as to its potency, for as little as $10 \mu \mathrm{g}$. by mouth has been sufficient to produce results. Psychotic patients, however, seem to be less sensitive and to require larger doses. When L.S.D. is taken by mouth symptoms appear within half an hour, reach their maximum in about two and a half hours, and gradually pass off in the following four to five hours. Occasionally mild after-effects are noted over the next few days.

The subjective complaints after a dose of L.S.D. are chiefly of headache, malaise, giddiness, nausea, feeling cold, anorexia, and palpitations. Objectively the examination of the autonomic and central nervous system is equivocal. On the other hand, psychological changes are prominent. Thought and speech may exhibit retardation, acceleration, blocking, and hesitancy; the speech may be slurred. The effect is one of euphoria, but depression as well as apprehension and depersonalization may occur. Disturbances of perception are common, especially in the visual sphere, as manifested by distortion, wrong perspective, or incorrect estimation of distances; colour perception may be poor or faulty. These effects increase with larger doses and may result in hallucinations. In the behavourial field under-activity with lack of initiative is most frequently observed, but restlessness and even agitation is sometimes noted. Unmotivated smiling and forced laughing have been described.

Busch and Johnson (1950) have drawn attention to the possible use of L.S.D. as an aid to psychotherapy since they found that psychotic patients responded with an increased production and verbalization of psychopathological material.

\section{EXPERIMENTAL}

Previous investigators gave L.S.D. by mouth. We, too, have used this route of administration in preliminary 
experiments, but later the drug was given by intravenous injection. This procedure, being independent of the individual variations in intestinal absorption, had the advantage of producing a more standardized and less protracted time curve of effects ; moreover the comparison with the effects of methedrine, which was also administered by intravenous injection, was facilitated. Forrer and Goldner (1951) found that L.S.D., when taken by mouth, is not toxic up to doses of $6 \mu \mathrm{g} . / \mathrm{kg}$. It was felt therefore that the intravenous injection would not involve undue risks. Initially small doses in the order of $25 \mu \mathrm{g}$. in $10 \mathrm{ml}$. of normal saline were used, but since these proved safe, the dose was eventually stepped up to $60 \mu \mathrm{g}$. dissolved in $5 \mathrm{ml}$. of normal saline. A stock solution of $1 \mathrm{mg}$. in $5 \mathrm{ml}$. saline was prepared and stored in the frozen state for not more than one week. It was further diluted immediately before use. Methedrine was employed in doses of 40 to $60 \mathrm{mg}$.

The subjects were investigated in the forenoon after an overnight fast. They were under constant observation in a quiet room and their psychological and neurological symptoms were noted. They were encouraged to lie down, but this was not insisted upon and they were allowed to move freely if they wished. Blood samples were withdrawn from the cubital veins before the injection and at five, 10, 20,30, 40, 60, and 90 minutes after the injection. In three patients who were examined after oral administration of $40 \mu \mathrm{g}$. L.S.D. blood samples were withdrawn before ingestion and $0.5,1,1.5,2,2.5$, 3 , and 3.5 hours after ingestion. Blood sugar was estimated in duplicate on $0.2 \mathrm{ml}$. samples of whole blood by the method of Nelson (1944) after $\mathrm{Ba}(\mathrm{OH})_{2}-$ $\mathrm{ZnSO}_{4}$ deproteinization. Adrenaline was determined on a sample of plasma according to Weil-Malherbe and Bone (1952).

Ten cases were investigated after the intravenous injection of L.S.D. and 11 after the injection of methedrine. Further patients who had been similarly treated are not included because of differing dosage or incomplete investigation. The two groups consist of an approximately equal number of male and female patients varying in age from 22 to 61 years. Four cases received both drugs in separate experiments. The diagnostic composition of the two groups is shown in Table $\mathbf{I}$.

TABLE I

SURVEY OF CASES INVESTIGATED

\begin{tabular}{|c|c|c|c|}
\hline \multirow{2}{*}{\multicolumn{2}{|c|}{ Diagnosis }} & \multicolumn{2}{|c|}{ Number of Cases } \\
\hline & & L.S.D. & Methedrine \\
\hline $\begin{array}{l}\text { Depression . } \\
\text { Paranoid schizophrenia } \\
\text { Other forms of schizophrenia } \\
\text { Anxiety hysteria } \\
\text { Psychopathic states .. }\end{array}$ & $\begin{array}{l}\cdots \\
\cdots \\
\cdots \\
\cdots\end{array}$ & $\begin{array}{l}3 \\
2 \\
4 \\
0 \\
1\end{array}$ & $\begin{array}{l}0 \\
2 \\
5 \\
2 \\
2\end{array}$ \\
\hline
\end{tabular}

\section{RESULTS}

\section{Symptomatology}

L.S.D. - The intravenous injection of L.S.D. produced a train of events occurring at a relatively constant time interval. After five minutes a flushing of the face was observed in five patients and seven patients appeared more relaxed and at ease. Some spontaneously commented on this with remarks such as, "I feel I can concentrate better", "I look at you relaxed". Talkative patients became calmer.

After 10 minutes mental symptoms became noticeable, chiefly in the sphere of thinking, speaking, and behaviour. While depressed patients became more retarded in both movement and speech, cataleptic phenomena were noted in some non-paranoid schizophrenics. Blocking, incoherence, perseveration, echolalia, poor production of material occurred in all six schizophrenics in various combinations, and in one of them the pupils became unequal and eccentric but reacted to light and convergence. After 15 to 20 minutes changes in mood and affect appeared. The mood fluctuated between euphoria, excitement, and depression. In the euphoric phase the subject may laugh happily, make erotic advances, propose marriage, and behave flippantly. The swingover to depression may take place rapidly and may be associated with crying, expressions of guilt, and occasionally the onset of abreaction; this may be followed, equally abruptly, by a swing of mood in the other direction. It is during this period that repressed material or new delusional thought contents may be produced. The emotions are appropriate to the thought content. Theseco rapid mood swings were observed in all schizophrenic and psychopathic cases and persisted for two to three hours. Depressive patients, however, showed a steadily enhancing gloom and an accentuation of ideas of unworthiness and of mental retardation.

Changes in autonomic functions were observed in five cases after about 30 to 40 minutes. They consisted in subjective and objective shivering associated with goose-flesh and piloerection on the forearms in the case of men.

In six of the cases a change in the mental picture occurred after about 40 minutes. Apprehension and tenseness increased, sometimes progressing to agitation. Others showed an increase of mannerisms and grimaces. Only two schizophrenic patients gave at this time evidence of visual and auditory hallucinations. They appeared frightened and were completely inaccessible. This relatively rare occurrence of hallucinations is in striking contrast to the experience of most other observers who gave the drug by mouth. Four other patients became increasingly restless and agitated and one retarded depressive woman screamed 
continuously for two hours. The patients seemed to feel an unexplainable sense of terror, clinging to the examiner and begging not to be left.

The symptoms gradually disappeared in the course of two to three hours. Occasionally a vague euphoria persisted for another day, but usually the effects of the injection had worn off by the afternoon.

Perception of external objects was in no way impaired. Size, distance, shape, and colour were accurately assessed. In none of our patients did depersonalization or derealization occur. This may have been due to the severe impairment of speech and inability of communicating, for we have noted that patients have looked at their arms and legs in a vague perplexed way, but direct questioning elicited no further information except in one patient who said, "I can't believe they are mine". Another complained that his body felt lanky and loose at the joints. Neurological examination revealed no abnormality and E.E.G. records were normal.

Methedrine.-The effects of methedrine are perhaps better known. The effects of a $60 \mathrm{mg}$.-dose of methedrine resembled in many ways those of a $60 \mu \mathrm{g}$.-dose of L.S.D., and this similarity was particularly obvious in those patients who received both drugs.

As with L.S.D. the initial feeling is one of relaxation, starting sometimes with a swimming or floating sensation or with a transient pounding in the head. At this stage one mild-mannered, quietspoken schizophrenic patient burst out swearing in a loud voice for about a minute and then said, "I feel marvellous now. Why isn't it like this all the time?". However, within five minutes he was speaking rapidly and incoherently and soon was maintaining any bizarre postures into which he was placed. He produced repressed material, but his speech became progressively slower and he became finally mute.

The appearance of cataleptic phenomena in varying degrees and for varying lengths of time was the rule for schizophrenic patients and was more marked than with L.S.D. Their speech may be incoherent, fragmentary, or delivered in telegraphic style, while blocking may occur in others.

The non-schizophrenic group exhibited pressure of talk which was always logical and often led to abreaction with resurrection of repressed material and much weeping and anguish ; this often resulted in a certain amount of relief and release from tension.

Mood fluctuations were not so prominent as after the injection of L.S.D. ; on the other hand, the mood often appeared to be incongruous, at least in the schizophrenic patients. They looked as if they were in absolute torment, but stated, "It is beautiful", or claimed to be in heaven. Generally the previous disposition of mood was retained or even accentuated during the experiment.

Objective evidence of hallucinations was present in every case of schizophrenia. One clinically recovered patient became acutely schizophrenic for the space of two hours. Ten minutes after the injection he started to mumble to himself, struck postures, and was completely inaccessible. When the effects of the drug had worn off he was none the worse for his experience although three months later he relapsed when home on trial.

The subjects treated with methedrine showed no disorders of perception either of their own body or of the external world.

Comparison of the Two Drugs.-A property common to both drugs is their capacity of intensifying the symptomatology and accentuating the clinical picture. In doubtful cases this has proved to be a real help in the diagnosis. Both drugs tend to increase tension as indicated by the appearance of cataleptic phenomena, by abreaction, and by the uncovering of delusional material. In this respect, and in the doses used, methedrine seemed to be more effective than L.S.D. Methedrine also induced hallucinations in schizophrenic patients more readily than L.S.D. Insomnia frequently followed the injection of methedrine, but not of L.S.D.

The chief point of difference between the two drugs is in their influence on the affect. The appearance of rapid mood swings, with predominant euphoria, seemed to be a feature of L.S.D. action only.

\section{Biochemical Observations}

Plasma Adrenaline Levels.-The changes in the plasma adrenaline concentration observed after the administration of the two drugs are recorded in Figs. 1-4. The results have been expressed as percentage differences from the pre-injection values. The thin lines represent the individual observations, while the heavy lines show the means of the individual observations after a given time interval, together with their standard errors.

The initial concentration of plasma adrenaline, determined as the mean of 23 observations, was $3.57 \pm 0.084 \mu \mathrm{g}$. $/ 1$. with a range from 2.80 to $4.26 \mu \mathrm{g} . / 1$. These figures are very close to those previously found (Weil-Malherbe and Bone, 1952).

Though there were considerable individual 


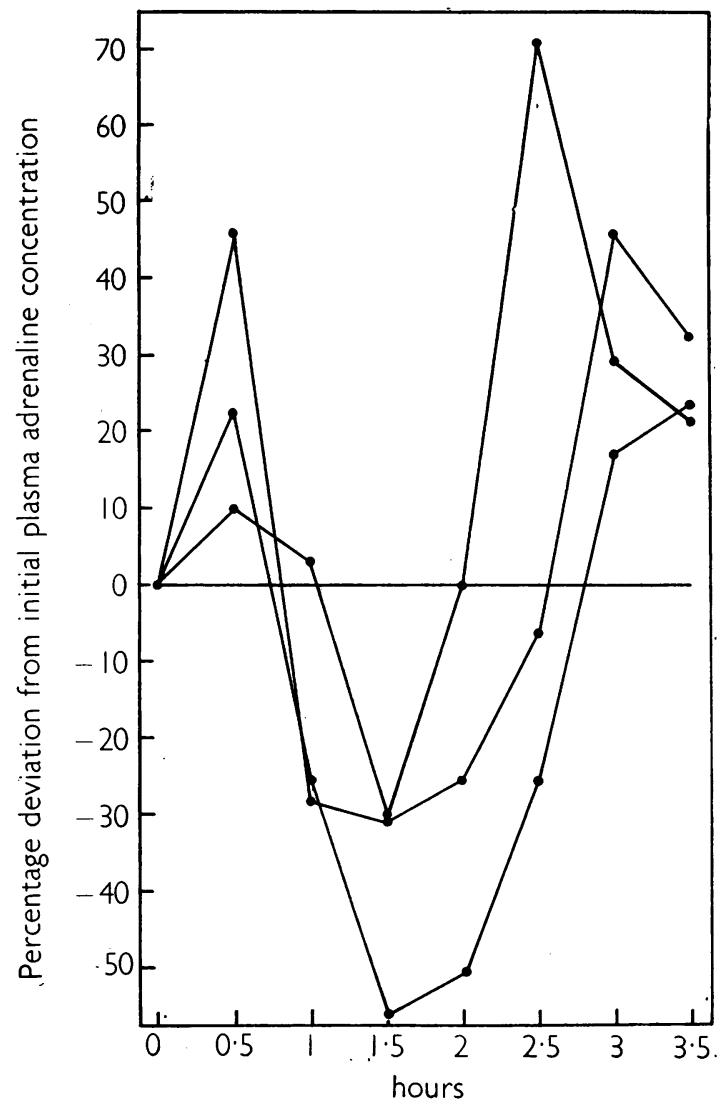

Fig. 1.-The effect of 40 to $60 \mu \mathrm{g}$. L.S.D. (by mouth) on the plasma adrenaline concentration.

variations in the response of the plasma adrenaline level to the administration of the drugs, the trend was similar in all cases and with both drugs. Broadly speaking, three phases could be distinguished: (1) an initial rise of plasma adrenaline; (2) a drop well below the base line ; and (3) a second rise to the level of the base line or above it.

The greatest variations between individual cases concerned the extent and duration of the first phase, especially when methedrine had been injected. While in some cases the initial rise of adrenaline was pronounced and lasted for 10 to 20 minutes, it was less marked and of short duration in others. In four of the cases injected with methedrine phase 1 was completely absent and the plasma adrenaline level showed a drop without any significant rise preceding it. These cases were considered separately and designated as "Type 2 " (Fig. 4). Clinically three of them were diagnosed as schizophrenia and one as psycho- pathic state. Of the seven cases which showed a "Type 1 " response, i.e. a well-marked phase 1 (Fig. 3), four were schizophrenics and three were psychopaths or neurotics. There was thus no obvious correlation between reaction type and diagnosis either in these experiments or in those performed with L.S.D., and in view of the small number of cases the results were not classified according to diagnosis.

Similar differences were observed after the intravenous injection of L.S.D. (Fig. 2). Though an initial rise of the plasma adrenaline level was found in four cases, it had always subsided after 10 minutes; in the other cases this phase was not in evidence at all. The course of events seemed to be similar to that after methedrine injection, but it seemed to proceed faster. Thus, the lowest level of plasma adrenaline was usually observed after five to 10 minutes in the L.S.D. experiments and after 20 to 30 minutes in the methedrine experiments. It is interesting to note that in the curves of plasma adrenaline concentration which were recorded after the oral administration of L.S.D. the three phases are well defined (Fig. 1). Though drawn on a different time scale, these curves more closely resemble some of the methedrine curves presented in Fig. 3 than do those obtained after the intravenous injection of L.S.D. and it seems reasonable to attribute the difference to the different rate of entry into the circulation.

In consequence of the different speed with which the three phases develop in different cases there is a considerable overlap when the individual curves are superimposed and many values which are

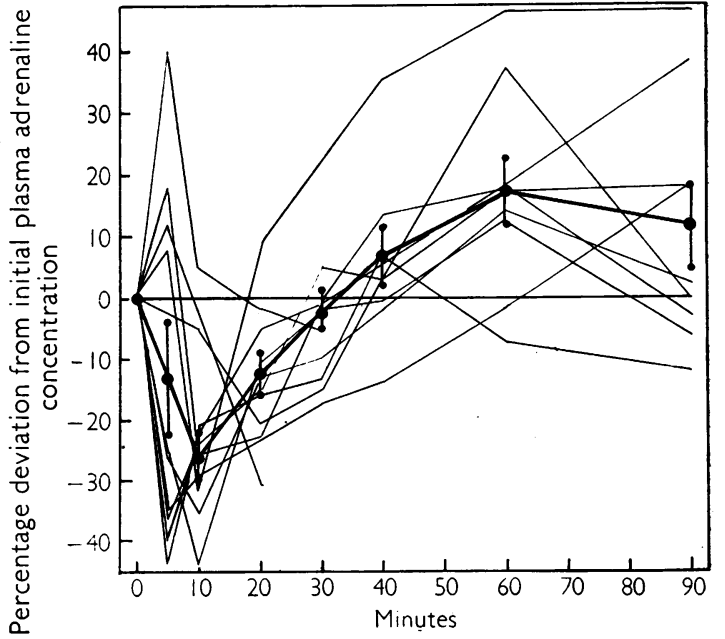

FIG. 2.-The effect of an intravenous injection of L.S.D. (40-60 $\mu \mathrm{g}$.) on the plasma adrenaline concentration. 


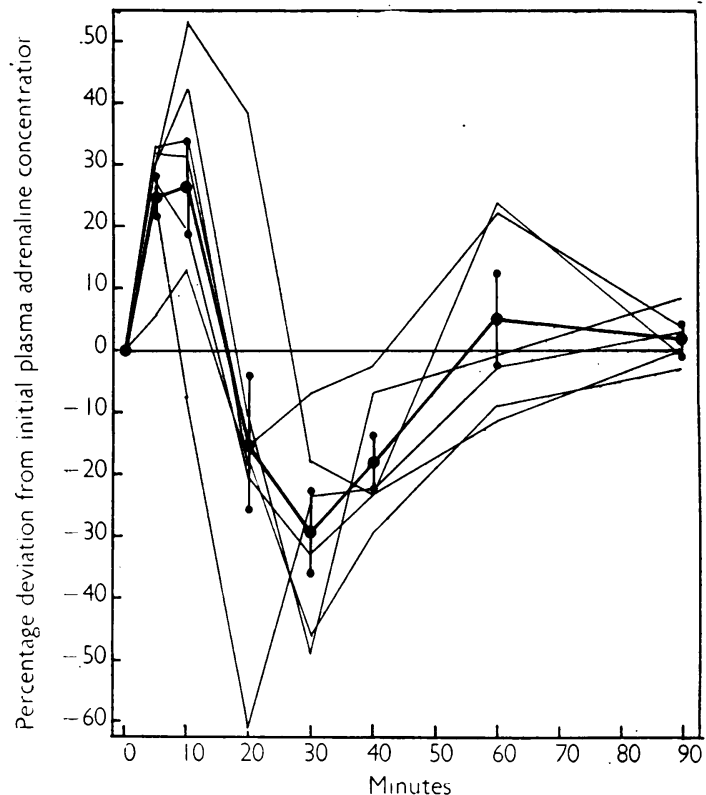

FIG. 3.-The effect of an intravenous injection of methedrine (40-60 mg.) on the plasma adrenaline concentration: Type 1.

significant in themselves tend to cancel each other out in the aggregate. The statistical significance of the means is thereby reduced. In spite of this, the main effects are statistically significant (Table II).

Blood Sugar Levels. - The percentage changes in blood sugar concentration after the injection of methedrine or L.S.D. are shown in Table III.
A significant rise of the blood sugar, by about $20 \%$, occurred after 30 to 40 minutes in those patients who reacted to methedrine injection with an initial rise of the adrenaline level (Type 1). By contrast no such blood sugar rise was found

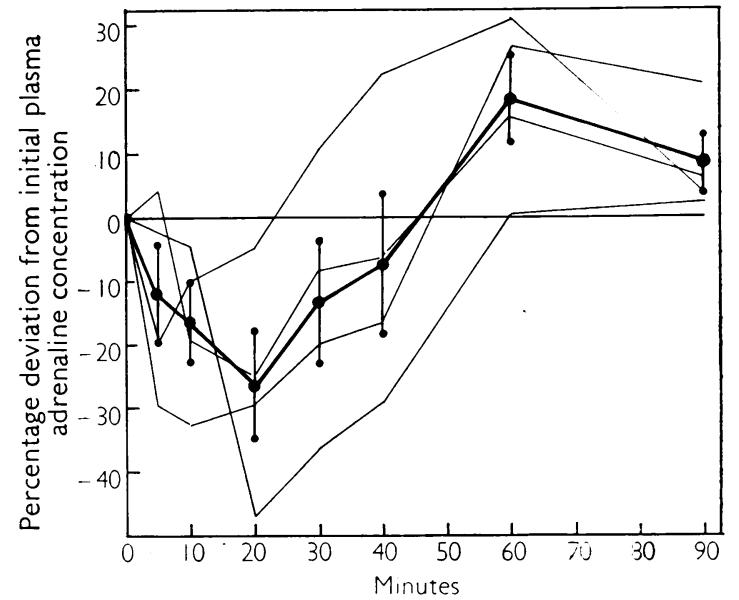

FIG. 4.- The effect of an intravenous injection of methedrine (40-60 mg.) on the plasma adrenaline concentration: Type 2.

in those cases in which the initial adrenaline rise was absent (Type 2) and a slight blood sugar rise of doubtful statistical significance was only found after 90 minutes. After the intravenous injection of L.S.D. a slight blood sugar rise, amounting in the average to about $6 \%$, occurred; it is on the borderline of statistical significance.

No clear-cut results were obtained after the

TABLE II

MEAN VALUES OF PERCENTAGE CHANGES OF PLASMA ADRENALINE CONCENTRATION AFTER INTRAVENOUS INJECTION OF L.S.D. OR METHEDRINE AND THEIR STATISTICAL SIGNIFICANCE

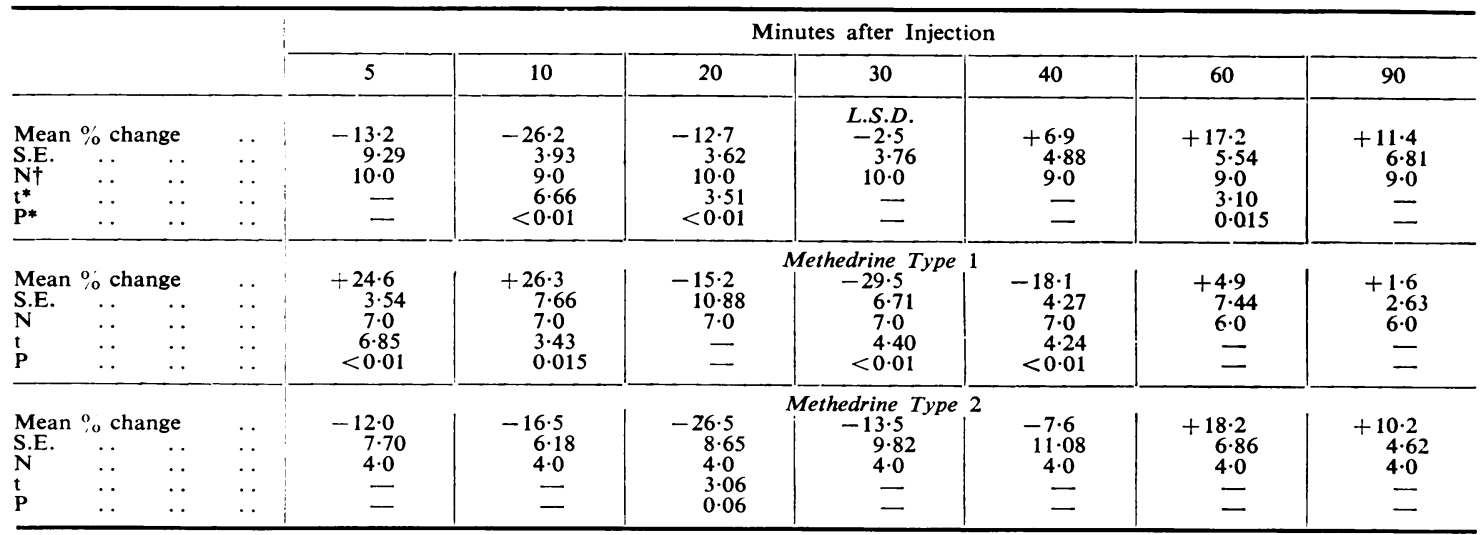

* Values of $\mathrm{t}$ (mean/S.E.) and $\mathrm{P}$ (probability of chance variation) are presented only where the mean changes are significant or nearly significant.

$+\mathrm{N}=$ no. of observations. 
TABLE III

MEAN VALUES OF PERCENTAGE BLOOD SUGAR CHANGES AFTER INTRAVENOUS INJECTION OF L.S.D. OR METHEDRINE

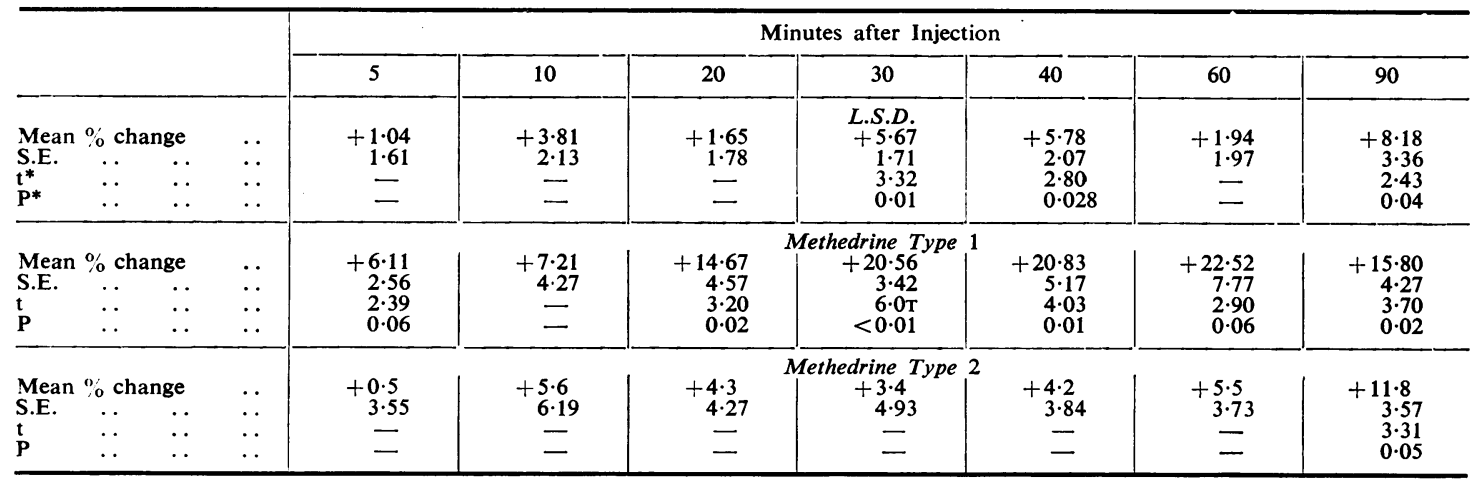

* Values of $\mathrm{t}$ and $\mathrm{P}$ are presented only where the mean changes are significant or nearly significant. No. of observations as in Table II.

oral administration of L.S.D. A slight initial increase of the blood sugar concentration was probably induced by the lactose powder as a diluent for the crystalline L.S.D.

\section{Correlation of Clinical and Biochemical Events}

On the whole, the phase of falling adrenaline concentration seemed to be associated with relaxation and euphoria, that of rising adrenaline concentration with tension and anxiety, often accompanied by a sensation of shivering and an appearance of goose-flesh. The case of a middle-aged woman suffering from endogenous depression has been described in an earlier section, who, 60 minutes after an injection of L.S.D., became extremely agitated and screamed continuously for about two hours. This case was also remarkable in showing an elevation of the plasma adrenaline concentration by about $50 \%$ above the starting value in the 60 - and 90 -minute samples, i.e. during the state of excitement (Fig. 2).

Until more is known about the response of the blood adrenaline level to the action of pharmaca and its bearing on psychological phenomena the significance of our findings cannot be fully assessed. One point, however, has clearly emerged : there is a great similarity between methedrine and L.S.D. not only in clinical effects, but also in their effects on the blood adrenaline level, a fact which strongly suggests that both effects are correlated.

\section{SUMMARY}

d-N-Methylamphetamine hydrochloride (" methedrine ") in doses of 40 to $60 \mathrm{mg}$. and lysergic acid diethylamide (L.S.D.) in doses of 40 to $60 \mu \mathrm{g}$. were given by intravenous injection to patients suffering from various mental disorders and their clinical and biochemical effects studied.

After an initial phase of relaxation both drugs produced an aggravation of the clinical picture : while depressive patients became more retarded and depressed, or more agitated, schizophrenic

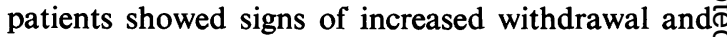
tension and an accentuation of catatonic and cataleptic features. Abreaction frequently occurred, especially in psychoneurotic patients.

Rapid mood swings were sometimes observed after the injection of L.S.D. Methedrine did not produce this effect, but it more readily provokedo hallucinations in schizophrenic patients.

The biochemical studies consisted in the determination of the plasma adrenaline and blood sugar concentrations. The effects of both drugs on the plasma adrenaline level were similar. Three phases could be distinguished after the injections : an initial rise of the adrenaline level, a drop below the starting level, and finally a secondary rise. Individual cases mainly differed in the speed with which these phases followed each other. Sometimes, and especially after the injection of L.S.D., the adrenaline level decreased before the initial rise could be observed. When, however, L.S.D. was given by mouth, the initial increase of the adrenaline concentration was clearly evident.

A moderate increase of the blood sugar concentration sometimes followed the injection of methedrine, but the effects of L.S.D. on the blood sugar concentration were hardly significant.

We wish to thank Messrs. Sandoz Ltd. for a generous gift of lysergic acid diethylamide. We gratefully acknowledge the technical assistance of A. D. Bone. 


\section{REFERENCES}

Becker, A. M. (1949). Wien. Z. Nervenheilk., 2, 402.

Busch, A. K., and Johnson, W. C. (1950). Dis. nerv. Syst., 11, 241. Condrau, G. (1949). Acta psychiat., Kbh, 24, 9.

De Giacomo U. (1951). Acta neurol, Napoli, 6, 1.

Delay, J. (1949). Proc. roy. Soc. Med., 42, 491.
DeShon, H. J., Rinkel. M., and Solomon. H. C. (1952). Psych:at. Quart., 26, 33.

Fischer, R., Georgi, F., and Weber, R. (1951). Schweiz. med. Wschr.,

Forrer, G. R., and Goldner, R. D. (1951). Arch. Neurol. Psychiat., Chicago, 65, 581 .
Hoch, P. H., Cattell, J. P., and Pennes, H. H. (1952a). Amer. J. Psychiat., 108, 579.

-1 (1952b). Ibid. 108,585

Hope, J. M., Callaway, E., and Sands, S. L. (1951). Dis. nerv. S.'st., 12, 67 .

Levine, J., Rinkel, M., and Greenblatt, M. (1948). Amer. J. Psychiat. $105,429$.

Nelson, N. (1944). J. biol. Chem., 153, 375.

Rudolf, G. de M. (1949). J. ment. Sci., 95, 920.

Stoll, W. A. (1947). Schweiz. Arch. Neurol. Psychiat., 60.

279. A. (1947). Schweiz. Arch. Neurol. Psychiat., 6.,
Weil-Malherbe, H., and Bone. A. D. (1952). Biochem. J., 51,311 . 